\title{
Correcting Nitrate Profiles Measured by the In Situ Ultraviolet Spectrophotometer in Arctic Ocean Waters
}

\author{
John P. Christensen ${ }^{1, *}$ and Humfrey Melling ${ }^{2}$ \\ ${ }^{1}$ Bigelow Laboratory for Ocean Sciences, 180 McKown Point, West Boothbay Harbor Maine 04575 USA \\ ${ }^{2}$ Fisheries and Oceans Canada, Institute of Ocean Sciences, 9860 West Saanich Road, P.O. Box 6000, Sydney, \\ $B C$, Canada V8L $4 B 2$
}

\begin{abstract}
A recently commercialized sensor, the In Situ Ultraviolet Spectrophotometer (ISUS), can determine seawater nitrate concentrations rapidly. Procedures for incorporating ISUS data within routine conductivity, temperature, and depth (CTD) profiling studies have not been described. Using a CTD system with an ISUS, vertical hydrographic profiles with nutrient concentrations were determined at 42 sites across the shelf break on the Beaufort Sea, Alaska. Key data processing steps included elimination of redundant nitrate values, shifting the ISUS data so as to be simultaneous with the CTD data, and correcting the ISUS output voltages for warm-up drift. After regressing the corrected ISUS output voltages against nitrate concentrations determined on bottle samples, the ISUS-estimated nitrate concentrations reproduced the bottle results within $+/-0.28 \mu \mathrm{M}$. The highly detailed ISUS profiles showed mesoscale intrusions of low nutrient water on the upper continental slope and strong nutrient upwelling near the shelf break.
\end{abstract}

Keywords: Nitrate Concentration, Ultraviolet Spectrophotometer, CTD Observations, CTD Processing, Arctic Ocean, Beaufort Sea.

With the recognition that the nitrate ion has a strong absorption peak in the lower ultraviolet spectrum below 230 $\mathrm{nm}[1-3]$, several separate approaches were developed which offered the potential for measurement of high-resolution nitrate distributions in near-surface waters of the oceans [4-9]. Several inorganic ions also absorb in this range of the ultraviolet spectrum [1,9-11], but most are found at such low concentrations in normal ocean waters so as not to interfere, with the exception of bromide [3, 11, 12]. One instrument, the In Situ Ultraviolet Spectrophotometer (ISUS), was developed at the Monterey Bay Research Institute [11] and became commercially available in 2003 (Satlantic Inc., Halifax NS). The ISUS illuminates a volume of natural seawater in a cell of fixed width $(10 \mathrm{~mm})$ and the absorption spectra is measured thrice. The instrument's microprocessor pools the resulting spectra, fits ideal nitrate and bromide absorbance spectra to the observed seawater spectra, and then calculates both these concentrations. Since bromide is conservative with salinity [13, 14], the bromide concentration is reported as a salinity. To correct for apparent absorbance due to dark current, every tenth spectrum is a dark scan in which the ultraviolet illumination is blocked. For the instrument used in our study (serial number 003), the manufacturer reported the usable nitrate range, accuracy, and precision to be $0.5-200 \mu \mathrm{M},+/-2 \mu \mathrm{M}$, and $+/-0.05 \mu \mathrm{M}$.

*Address correspondence to this author at the Bigelow Laboratory for Ocean Sciences, 180 McKown Point, West Boothbay Harbor Maine 04575 USA; Fax: 207-633-9641; E-mail: jchristensen @ bigelow.org
Based on conductivity, temperature, depth (CTD) and ISUS data collected in the Beaufort Sea north of Alaska, we developed the processing procedures for the ISUS data collected during routine CTD vertical profiling. Specifically, our routines eliminated redundant measurement values, corrected for time-delay and for the warm-up drift found in the ISUS data. The results were compared and normalized to measured nitrate concentrations from bottle collections of seawater, which showed that ISUS data can correctly estimate seawater nitrate concentrations to within $0.28 \mu \mathrm{M}$.

We employed an ISUS in a CTD/nutrient survey of the northern Alaskan shelf-slope region in April 2003 (Fig. 1). In the space of 2 weeks, we sampled 42 sites by helicopter. At each site, a $20 \mathrm{~cm}$ diameter hole was augured through the sea-ice (average ice thickness of $138 \mathrm{~cm}$ ). A Seabird CTD (SBE 25) linked to our ISUS was connected to a conducting cable, winch, and deck unit. The instrument string was deployed through the hole in the sea-ice and vertical profiles to depths as great as $390 \mathrm{~m}$ were measured. A bottom trip-weight electronically indicated to both the CTD and the deck unit the occurrence of the sediment surface $5 \mathrm{~m}$ below the CTD, so that the instruments were not implanted into the mud. A single oceanographic sampling bottle was used to collect water from up to 7 depths at a site, so that within a single CTD cast, the CTD, ISUS, and water bottle were repeatedly lowered and raised until all water samples were collected. For nutrient determinations, about $20 \mathrm{ml}$ of seawater was frozen in previously acid-cleaned and thoroughly dry polyethylene sample bottles. The nutrient samples were kept frozen until measurement at the Scripps Institute of Oceanography's Nutrient Chemistry Laboratory, 
which operates the nutrient autoanalyzer according to WOCE protocols for accuracy and precision. Of the nutrients that were measured (nitrate, nitrite, ammonium, inorganic phosphate, and dissolved silicate), only nitrate concentrations are reported here.

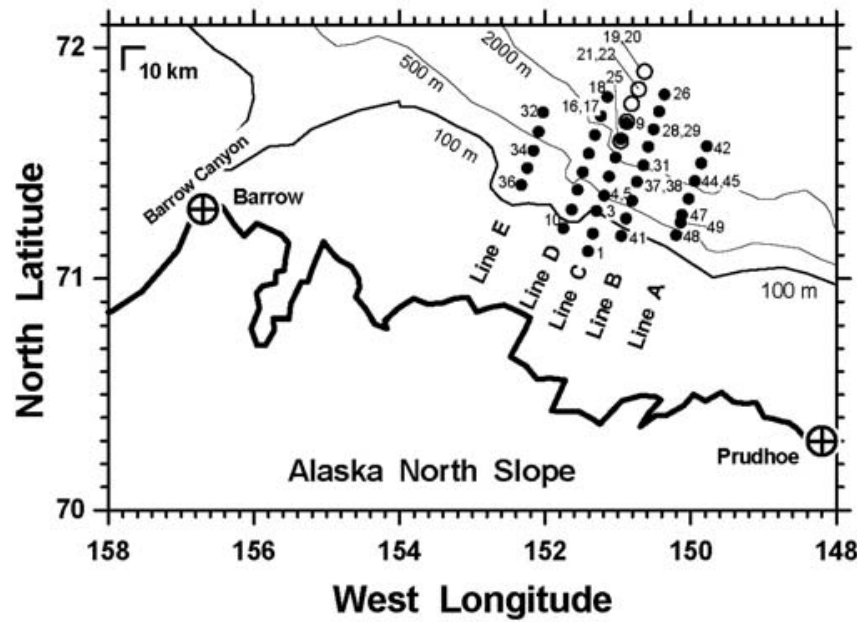

Fig. (1). Locations of CTD cast numbers sampled in the Beaufort Sea, Alaska, in April 2003.

The ISUS presented a number of technical issues in order to be linked to the Seabird CTD. First, it consumed large amounts of power which exceeded the supply available from the CTD. So, we provided a separate pressure case containing a battery pack (two sets of 12 alkaline D-cells connected in parallel) which supplied the operating current of about 0.8 amperes, sufficient for 4 hours of profiling. Secondly, when the ultraviolet lamp first was turned on, the ISUS drew 2-4 times as much current as when it was routinely running. This startup surge exceeded the surge capacity of the battery back, so we turned on the ISUS using a power supply running from a portable generator. Once the instrument was scanning, we then turned on the battery pack and disconnected the generator power. This initial startup was accomplished as the ISUS was about to be deployed through the sea-ice. Once the ISUS was running, the instrument string was lowered into the ocean and the CTD turned on. The ISUS output two analog channels to the CTD, one channel for the computed nitrate concentration and one for the ISUS-estimated salinity. These voltages, proportional to the ISUS-calculated nitrate concentration and ISUS-estimated salinity and scaled between 0 and 5 volts, were stored in the CTD records and are the basic data used in this study.

The CTD data was processed using SeaSoft post-cast processing software from Seabird Inc. Two forms of the CTD data are presented here: (a) profile data that were corrected for alignment, wild data editing, cell temperature equilibration, and low pass filtering, and which retained data in the data files by order of increasing elapsed-time during the cast, and (b) final pressure-binned data. The elapsed-time data maintains the individual determinations at each CTD sampling interval for the entire CTD cast. Occasionally, ice chunks would be drawn into the CTD during its initial lowering through the sea-ice hole, and the initial measurements of a cast might indicate constant low temperatures and diluted salinities, until the ice chunks melted or were pumped out. In the elapsed-time CTD records, anomalous temperature and salinity data were assigned a "no-data" value so that the temperature or salinity datum would be ignored by further processing routines. However, since the sampling tip of the ISUS was open to the ambient seawater, and not part of the CTD pumped water, ISUS data contained in the elapsed-time record typically was free of these inaccuracies and its data was retained unaltered. We used this elapsed-time data as described below to develop a protocol for processing the ISUS measurements. As the next step in data processing of the CTD data, the elapsed-time data from each cast was then binned into $0.5 \mathrm{dbar}$ pressure bins and the average pressure, temperature, and salinity within each bin was determined. This binned data represents the final CTD data [15] and is available in the Arctic System Science data repository at the web site of the Earth Observing Laboratory (EOL) of the University Consortium for Atmospheric Research (UCAR, web site: http://data.eol.ucar.edu/codiac/ arcss/).

Although a number of recent publications have reported initial results from UV measurements of ocean nitrate concentrations $[5,6,8,9,12]$, none have described in detail the procedures needed to routinely incorporate the ISUS output into oceanographic CTD profile data. Here, we describe the development of our processing procedures.

The first step in processing of the ISUS profile data was elimination of redundant values. When operating routinely, the ISUS scans the ambient seawater, processes the resulting spectra, and yields one output record in digital form. If the ISUS is set to output analog voltages for nitrate concentration and ISUS-estimated salinity, as done in our study, the digital to analog converter within ISUS produces a voltage commensurate with each concentration and then maintains this voltage until the next ISUS output record is produced. Since the speed of sampling of the ISUS was about $0.29 \mathrm{~Hz}$ while the SBE 25 CTD was recording at $8.0 \mathrm{~Hz}$, multiple records of CTD data within the elapsed-time data file contained a single unvarying voltage for nitrate and a single unvarying one for ISUS-salinity, even though no ISUS measurements were actually made at the instant of the CTD measurements. We wished to eliminate these redundant ISUS voltages and to retain only the first nitrate voltage and first salinity voltage supplied by ISUS after a new ISUS scan was completed. The first computer routine we developed was one that searched the elapsed-time data file looking for changes in ISUS nitrate and salinity voltages at about the frequency of every 3.5 seconds. Non-changing voltages not at this frequency were assigned to "no-data" values.

The second correction applied to the ISUS data was to shift the ISUS elapsed-time data back in time to the approximate time of determination of the second of three seawater spectra. The manufacturer listed the approximate time required to measure one spectra as $0.8 \mathrm{~s}$. Our evaluation of changes in the ISUS voltages indicated a total time for sampling and processing of $3.5 \mathrm{~s}$. Therefore, the time in the middle of the second spectral scan would have been about $2.3 \mathrm{~s}$ prior to the recording of the ISUS voltage within the CTD record. Thus, all ISUS voltages were moved backward in the elapsed-time data set by 2.3 seconds. Since the winch speed during profiling sometimes exceeded 70 $\mathrm{m} / \mathrm{min}$, this time shift would correspond to as much as a 3 
dbar difference in pressure. This resulted in a data file for each CTD cast, called the time-corrected data, which had actual ISUS measurements simultaneous with the CTD measurements.

Examination of these time-corrected data for all the CTD casts showed that $26 \%$ of the casts had ISUS data which appeared to drift to lower voltages as the cast continued, $33 \%$ of the casts had ISUS data which drifted to higher voltages as the cast continued, and $41 \%$ showed very constrained voltages as if no drift was occurring. We show three different casts where the ISUS nitrate voltages were plotted versus pressure (Fig. 2). Data from different time periods within the cast were separately colored. In CTD 13 (Fig. 2A), the profile made during the first $600 \mathrm{~s}$ of the cast showed surface nitrate values of 0.85 volts and values at 200 dbar of 1.22 volts. As the cast continued, these voltages
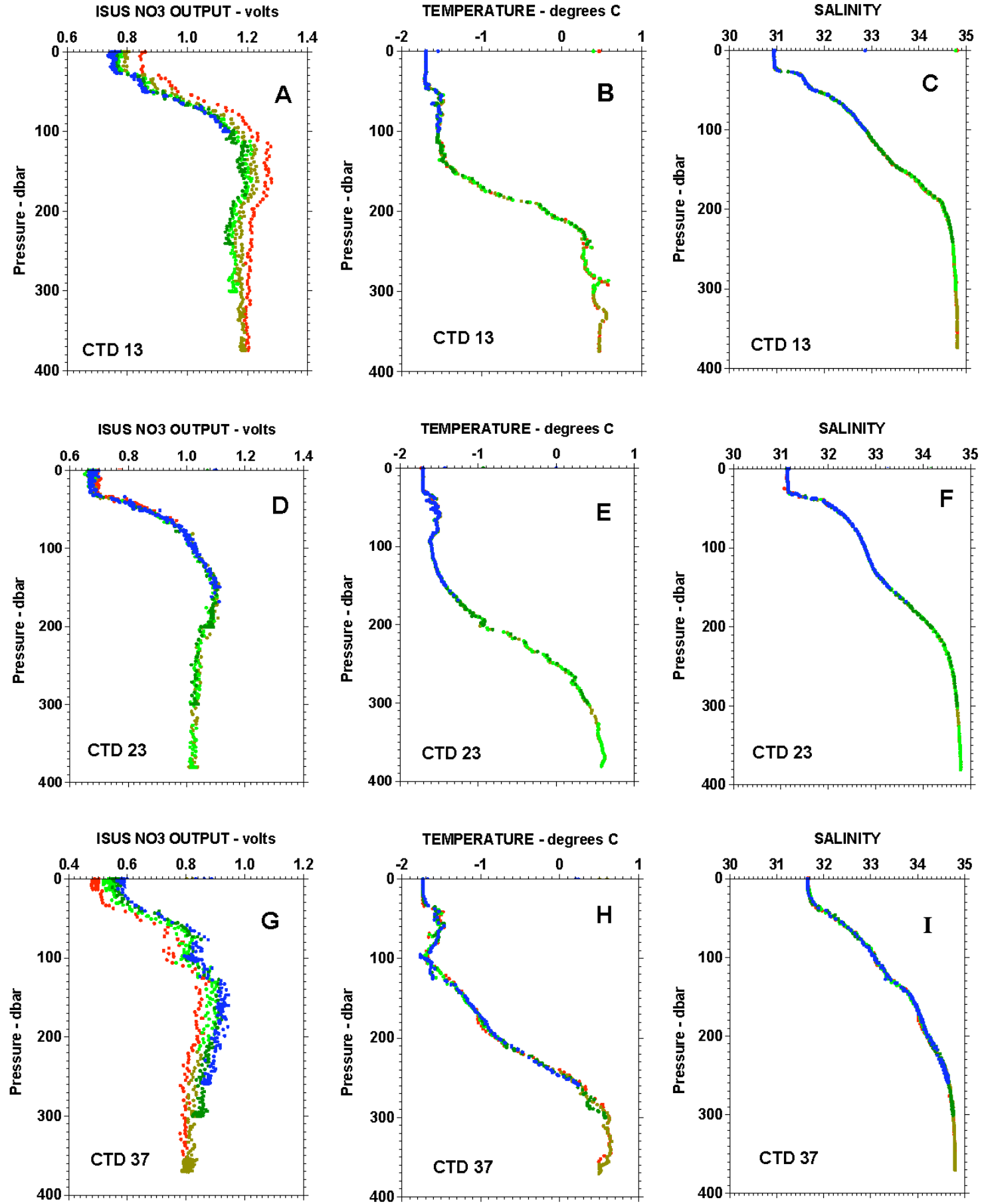

Fig. (2). Profiles of ISUS nitrate output voltage, temperature, and salinity during three CTD casts. Top sets are from CTD cast 13 , middle sets are from CTD 23, and bottom sets are from CTD 37. Data recorded in different periods of elapsed time during the casts are colored separately, red is less than 600 seconds, dark yellow is 600-1200 s, light green is 1200-1800 s, olive green is 1800-2400 s, and blue is greater than $2400 \mathrm{~s}$. 
drifted to lower values. For all data after $1800 \mathrm{~s}$, the surface voltages appeared stable at about 0.75 volts, and at $200 \mathrm{dbar}$ the ISUS output was 1.14 volts. In contrast, at CTD 37 (Fig. 2G), the apparent drift in voltages was from a lesser output to a greater output. At CTD 23 (Fig. 2D), the data at each pressure level were tightly clustered throughout the cast, suggesting that the ISUS output was stable over the time of the cast. Using the elapsed-time CTD data from each cast (Fig. 2B, 2C, 2E, 2F, 2H, 2I), both temperature and salinity data were tightly clustered at each pressure level, indicating that the temperatures and salinities were not changing over the approximate hour the instruments were in the water at any of these stations. Finally, the bottle collected nitrate concentrations showed a tightly constrained relationship with salinity at all stations, and these three stations match the general relationship (Fig. 3). Given the small variance of the bottle nitrate concentrations around the straight line relationships with salinity data (Fig. 3), and given the small variance in the salinity profile from each of the three example sites (Fig. 2C, 2F, 2I), if ISUS voltage output consistently reflected actual nitrate concentrations, then the ISUS nitrate profiles should have showed a very small variance, about the magnitude demonstrated for CTD cast 23 (Fig. 2D). The actual ISUS profiles from CTD 13 and 37 (Fig. 2A, 2G) showed considerably greater variance, suggesting that, at times, the ISUS output drifted during the period of time that the instrument was warming up.

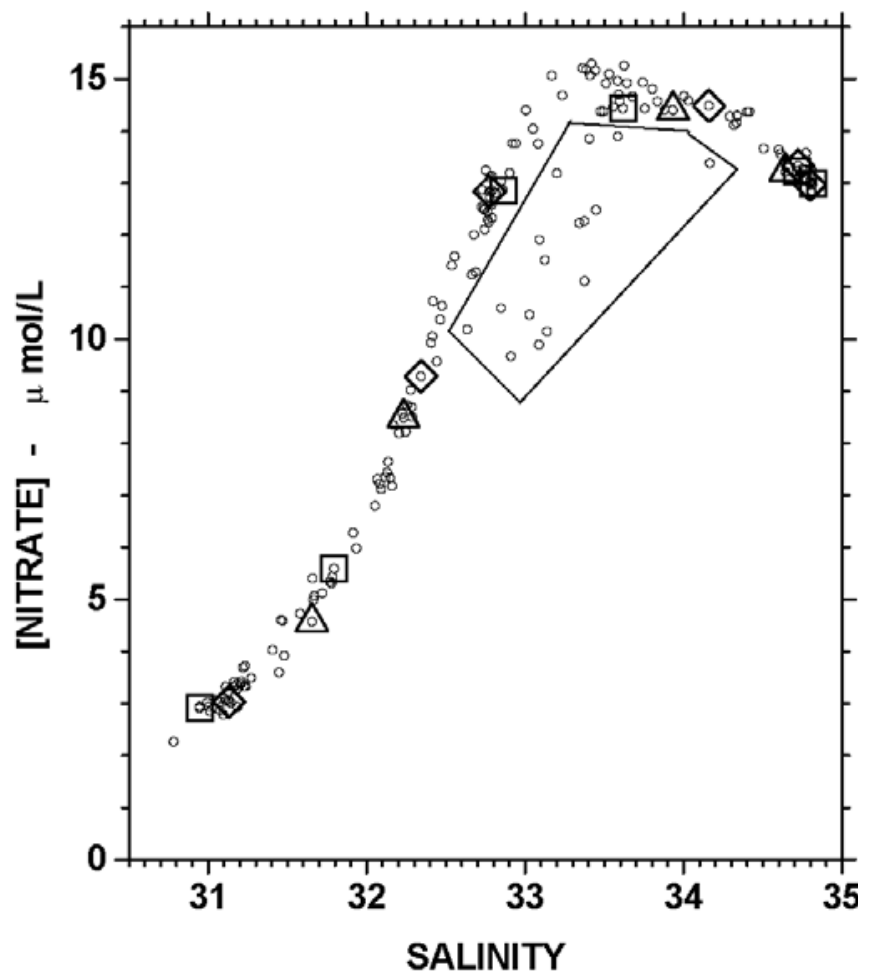

Fig. (3). Relationship of all bottle-collected nitrate samples with salinity (open circles) for all sites in the Beaufort Sea study. Those samples from CTD 13 are squares, those from CTD 23 are diamonds and those from CTD 37 are triangles. The sixteen samples within the polygon appear to be anomalous relative the general nitrate-salinity trends.
In the laboratory, we examined the stability of the ISUS output versus operating time over the first 3600 s. after starting up. For these tests, we constructed a constanttemperature bath in which the ISUS could be fully immersed in water of a constant temperature; while at the same time, we could change samples for ISUS measurements. In these warm-up tests, the unpowered ISUS was allowed to come to thermal equilibrium with the bath, the ISUS sampling tip was immersed in the desired sample, and the instrument was turned on and let run for up to 2 hours measuring the same sample. Although some warm-up experiments showed no great change in output over the first hour of operation, many showed an increasing voltage with elapsed time, while many other runs showed a decreasing output with elapsed time (Fig. 4). The direction of this drift (up or down) and magnitude of the drift did not seem to relate to nitrate or bromide concentrations being measured nor to the bath temperature. Nevertheless, we found that the equation that most frequently described the time-dependent output (Fig. 4) was an exponential one:

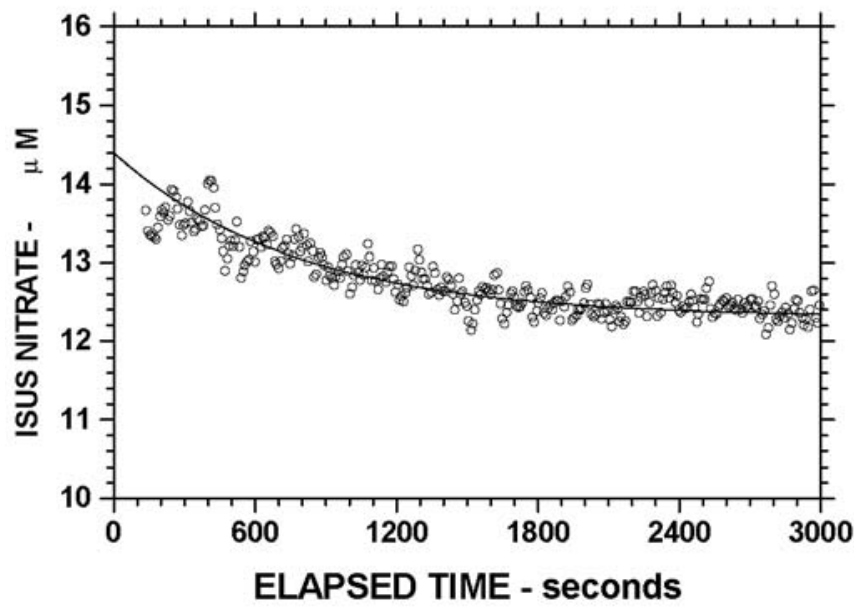

Fig. (4). Results from a laboratory-run warm-up experiment where the ISUS was sampling a $19.8 \mu \mathrm{M}$ nitrate solution in pure water pumped via a flow-through cell past the ISUS sampling tip. The ISUS was in a water bath maintained at $1.7^{\circ} \mathrm{C}$. The circles show the nitrate concentrations $\left(\mathrm{V}_{\mathrm{i}}\right)$ reported in the ISUS data records and the line represents the fit to equation 1 , where $\mathrm{V}_{\infty}$ is the fit value of $12.3 \mu \mathrm{M}, \mathrm{V}_{\mathrm{o}}$ is the fit value of $14.4 \mu \mathrm{M}$, and $b_{v}$ was estimated as $.00130 \mathrm{~s}^{-1}$. Elapsed time $\left(\mathrm{t}_{\mathrm{i}}\right)$ is from the time of day of the first ISUS record.

$$
\mathrm{V}_{\mathrm{i}}=\mathrm{V} \infty+\left(\mathrm{V}_{\mathrm{o}}-\mathrm{V} \infty\right) \exp \left(\mathrm{b}_{\mathrm{v}} \mathrm{t}_{\mathrm{i}}\right),
$$

where $V_{i}$ is the output voltage at any time, $t_{i}$. The voltages, $\mathrm{V}_{\mathrm{o}}$ and $\mathrm{V}_{\infty}$, are the voltage at the $\mathrm{t}_{\mathrm{i}}=0$ and at infinite time after the ISUS was turned on. The factor, $b_{v}$ with units of $s^{-1}$, is the exponential coefficient of time.

If warm-up drift were responsible for the time-changing profiles seen in some of our stations (e.g. CTD 13 and 37), then equation 1 should closely approximate the timedependent change in ISUS nitrate voltage seen in one of these drifting profiles. At any depth where sufficient numbers of ISUS measurements were made over a significant proportion of the elapsed time of the cast, equation 1 should closely describe the data, given that each depth will have a different value of $\mathrm{V}_{\mathrm{o}}$ and $\mathrm{V}_{\infty}$. Since each cast represented the 
equivalent of one laboratory-based warm-up experiment, a single value of the exponential coefficient (typically $0.000832 \mathrm{~s}^{-1}$ ) was found to apply for the entire cast. We note that the temperature of the waters were relatively uniform, varying between $-1.7^{\circ} \mathrm{C}$ in the near-surface waters just below the ice-pack to $+0.6^{\circ} \mathrm{C}$ at depths below $300 \mathrm{~m}$. Consequently, dramatic vertical temperature changes in the upper ocean, which might have impacted the electronics of the ISUS, was not a significant factor in our results. To evaluate warm-up drift, the time-corrected ISUS data were binned as done for the CTD data, and equation 1 was fit to the data within each bin. With $b_{v}$ fixed, the data in each bin was fit using a numerical routine that searched for values of $\mathrm{V}_{\mathrm{o}}$ and $\mathrm{V}_{\infty}$ that gave the best chi-squared fit (Fig. 5). Examination of the best fits from each station showed that the voltage difference, $\left(\mathrm{V}_{\mathrm{o}}\right.$ $-\mathrm{V}_{\infty}$ ), was relatively constant within an individual CTD cast. Using the average from the particular station, $\left(\mathrm{V}_{\mathrm{o}}-\mathrm{V}_{\infty}\right)_{\mathrm{ave}}$, equation 1 was inverted in order to calculate $V_{\infty}$ for each CTD record in the elapsed-time time-corrected data.

$\mathrm{V} \infty=\mathrm{V}_{\mathrm{i}}-\left(\mathrm{V}_{\mathrm{o}}-\mathrm{V} \infty\right)_{\text {ave }} \exp \left(\mathrm{b}_{\mathrm{v}} \mathrm{t}_{\mathrm{i}}\right)$

Two profiles of $\mathrm{V}_{\infty}$ are shown (Fig. 6) and represent the vertical distribution of ISUS nitrate output corrected to the fully warmed state of the ISUS. In profiles with significant warm-up drift, the resulting correction greatly reduced the variance at all depths in the profiles. For the time-corrected ISUS output voltages from CTD 13 (Fig. 6), the average standard deviation of all pressure bins with 2 or more data ( $n=174$ ) was 0.01663 volts, but after correction to the fully warmed state, the average standard deviation for all pressure bins was reduced to 0.00373 volts, a 4.4 fold reduction in the average standard deviation of replicate measurements during the cast. For CTD 37, the average standard deviation for all pressure bins with 2 or more data $(n=180)$ was 0.01792 volts, but after drift correction, the average standard deviation was reduced to 0.00846 volts, a 2.1 fold decrease in the standard deviation. Thus, the correction of the ISUS output voltages to the warmed state allowed much greater precision on the final nitrate concentration estimates from the ISUS output.

To complete the ISUS nitrate output profiles, the ISUS data was binned by pressure and averaged as done for the CTD data. Finally, on the CTD-ISUS instrument string, the CTD sensors were at the bottom of the string while the ISUS was mounted with its sensor tip facing upward just below water sample bottle at the top of the instrument string. Thus, the ISUS sensor was detecting water $2.5 \mathrm{~m}$ shallower than the CTD. The pressure of each ISUS output binned average was adjusted for the difference in height by shifting the ISUS bin averages to bins 2.5 dbar shallower.

Given the final ISUS voltage profile, all ISUS voltages at depths corresponding to the bottle collections at the station were regressed against measured nitrate concentrations, and the results used to convert the final ISUS voltage profile to ISUS-estimated nitrate concentrations (Fig. 7). The difference between the ISUS-estimated profile and the bottle nitrate concentration was found to be $0.0 \mu \mathrm{M}$ (average) +/$0.28 \mu \mathrm{M}$ (standard deviation) for 143 bottle samples, indicating that the ISUS-estimated nitrate concentrations reproduced the bottle concentrations within $+/-0.28 \mu \mathrm{M}$. We show the resulting nitrate profiles for our three example CTD casts $(13,23$, and 37) and the agreement with the bottle nitrate concentrations (Fig. 8). Final ISUS nitrate profiles and water bottle samples are available at the UCAR ARCSS web site $[16,17]$.
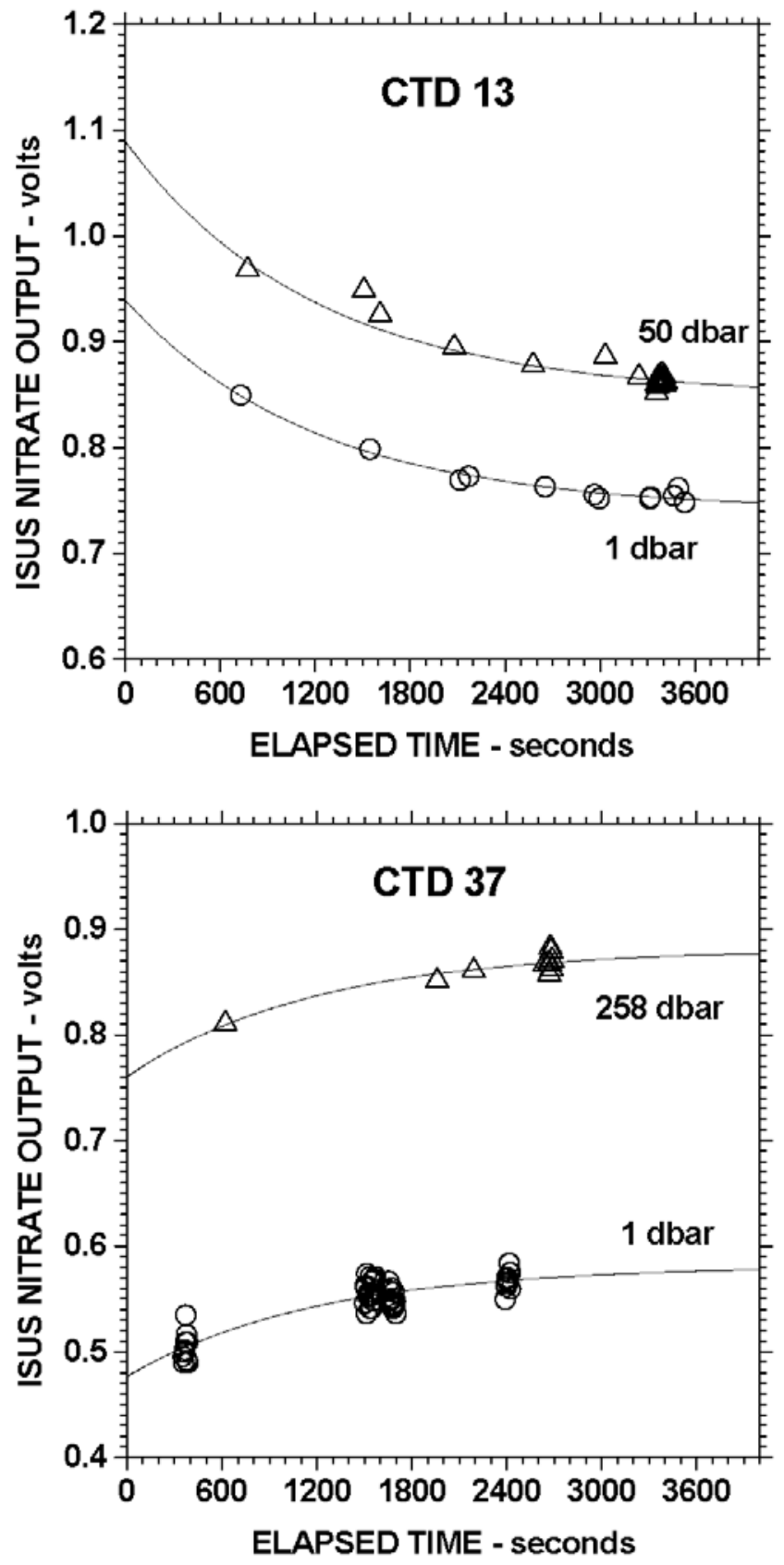

Fig. (5). Fits of ISUS output voltages to the exponential drift equation. Top panel is from CTD 13 for pressure bins of $1 \mathrm{dbar}$ and 50 dbar. The fit voltages were 0.9397 for $\mathrm{V}_{\mathrm{o}}$ and 0.7407 for $\mathrm{V}_{\infty}$ of the $1 \mathrm{dbar}$ bin, while these voltages were 1.0892 and 0.8488 for 50 dbar. Bottom panel is from CTD 37 for pressure bins $1 \mathrm{dbar}$ and 258 dbar. The fit voltages $\left(\mathrm{V}_{\mathrm{o}}\right.$ and $\left.\mathrm{V}_{\infty}\right)$ were 0.4556 and 0.5752 for $1 \mathrm{dbar}$ and 0.7605 and 0.8815 for $258 \mathrm{dbar}$. The coefficient, $\mathrm{b}_{\mathrm{v}}$, was $0.000832 \mathrm{~s}^{-1}$.

From the final nitrate profile results, the ISUS data provided several important results. First, in CTD 37, the ISUS based nitrate profile showed an apparent intrusion of lower-nitrate waters between the depths of 80 and 140 dbar 
ISUS NITRATE OUTPUT - volts ISUS NITRATE OUTPUT - volts
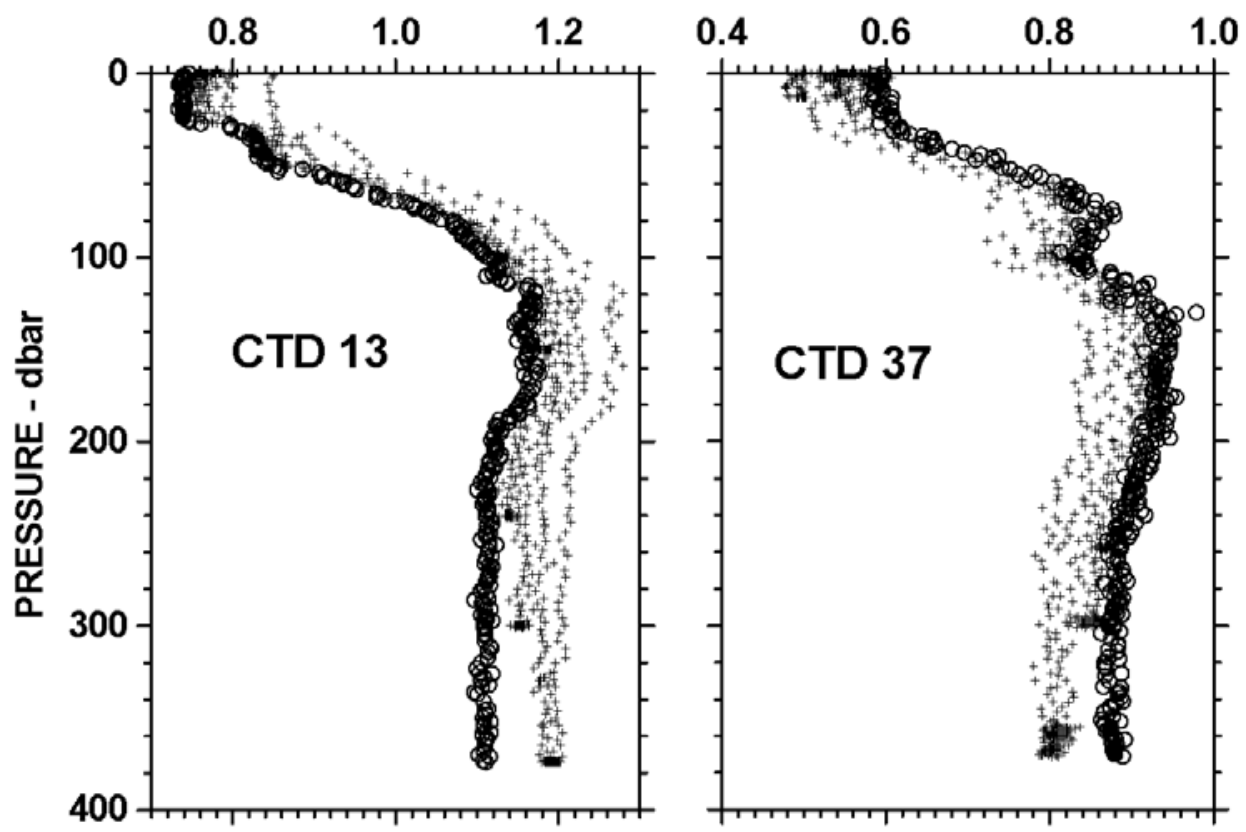

Fig. (6). Profiles of ISUS nitrate output voltage uncorrected for warm-up drift (crosses) and after correction for warm-up drift (open circles). At all depths, the variance of the profile was greatly improved by correcting for warm-up drift. Left panel is for CTD 13 while the right panel is for CTD 37.

(Fig. 8). This type of intrusion was seen in the ISUS data from a small subset of stations within our sampling grid. Only occasionally did our bottle samples collect water from these intrusions, and the bottle data in Fig. 3 showed approximately 16 samples in the range of 32.6 to 33.6 salinities with lowered nitrate concentrations relative the general trend. Based solely on the water bottle samples, these could have been evaluated as the result of erroneous bottle collections. However, the agreement of the ISUSestimated profiles with these apparently anomalous bottle values demonstrated the occurrence of these intrusions and provided detailed resolution about their extent. In a manuscript soon to be submitted, we will show that these intrusions are related to the mesoscale eddy structure in the sampling grid.

Secondly, the ISUS data also defined the near-surface nitrate concentrations in better detail than we would have had with just the bottle collections. We used the ISUS-based profiles to determine vertical sections of the nitrate along the sampled transect lines (Fig. 1). The vertical section along transect line B showed that shallow isopleths (those $<100$ dbar) of nitrate, salinity, and temperature, all occur at much shallower depths within $30 \mathrm{~km}$ of the shelf-slope transition than found further offshore (Fig. 9). These rising isopleths (from offshore to the shelf break) indicated the occurrence of shelf edge upwelling which contributed to enriched nitrate concentrations found within the upper $40 \mathrm{dbar}$ of the water column near the shelf break [18-20].

In conclusion, the ISUS data provided a powerful method of evaluating the detailed nitrate distributions in the nearsurface ocean, but some investigators have reported large uncertainties $(>1 \mu \mathrm{M})$ in the resulting nitrate concentrations

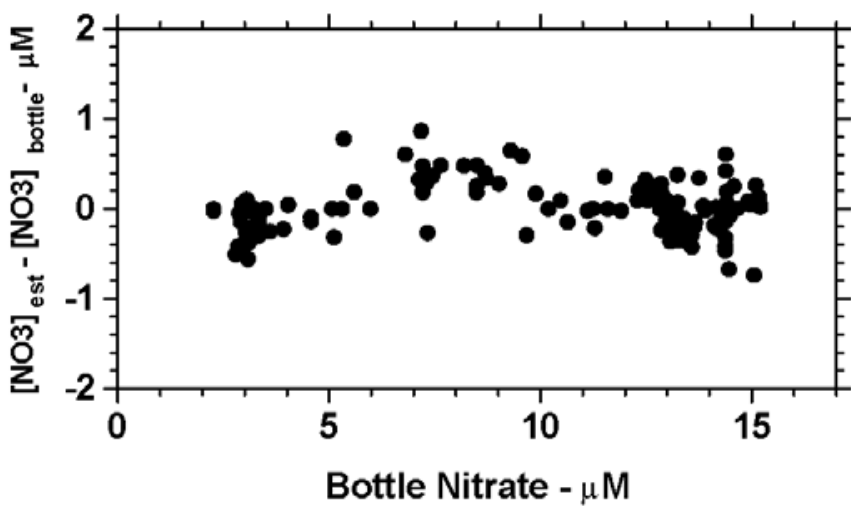

Fig. (7). Relationship between the difference between ISUS based nitrate concentration estimates and the bottle concentrations versus the bottle concentration. Averaging over all comparisons $(n=143)$, the mean and standard deviation was $0.00 \mu \mathrm{M}$ and $0.28 \mu \mathrm{M}$, indicating that the ISUS gave estimates of nitrate within $+/-0.28 \mu \mathrm{M}$ of the bottle nitrate measurements.

[9, 12]. Details of the incorporation the ISUS output into CTD data has received little attention. By considering the details of the operation of the ISUS, we chose a multi-step processing approach, where (1) we eliminated redundant nitrate values from the CTD data list, and then (2) we shifted the ISUS back in time so that the spectral measurements were simultaneous with the CTD measurements. The largest uncertainty was an output signal from the ISUS which drifted as the instrument warmed during a cast. At some stations the drift was to higher voltages (33\% of the casts). At others, it was to lower voltages ( $26 \%$ of the casts). Some stations showed no apparent drift (41\% of the casts). The 

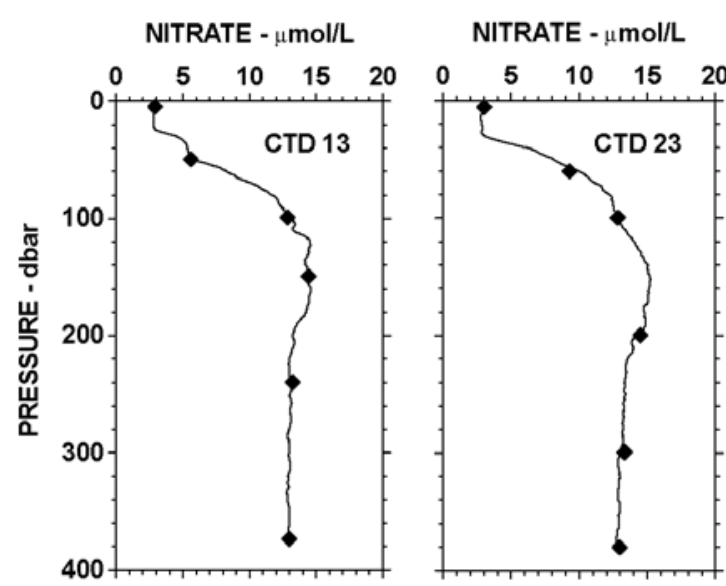

NITRATE - $\mu \mathrm{mol} / \mathrm{L}$

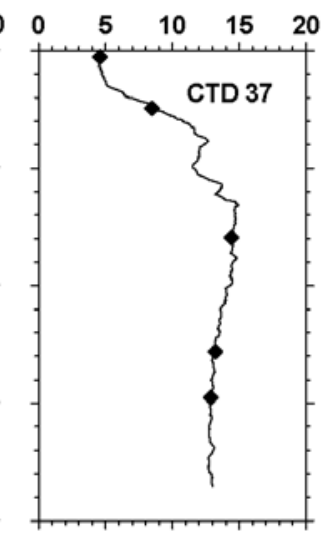

Fig. (8). Three vertical profiles of ISUS estimated nitrate concentrations (lines) and the bottle determined nitrate concentrations (diamonds). Right panel is for CTD 13, center panel is for CTD 23, and left panel is for CTD 37.
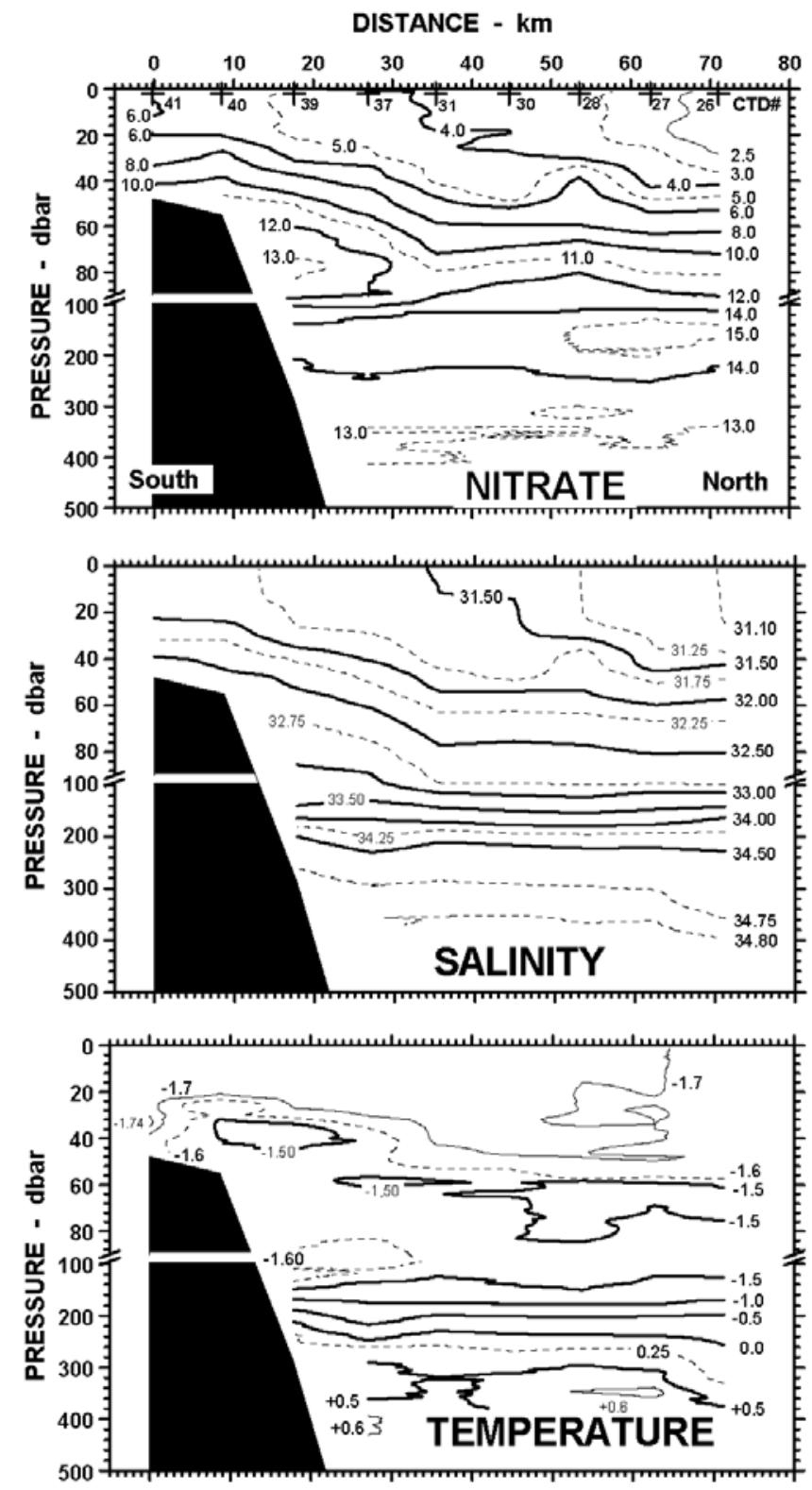

Fig. (9). Vertical sections of ISUS nitrate concentrations, salinity, and temperature along transect line B. Sections show rising isopleths of nitrate, salinity and temperature near the break between the continental shelf and continental slope, indicating shelf-edge upwelling. 
manner of this drift was consistent with drift observed in laboratory-run warm-up experiments conducted under controlled conditions. Based on each individual CTD cast, a procedure was developed which performed a chi-squared fitting routine on all data collected from the individual depths. The procedure proved successful in reducing the warm-up drift observed in many of the sampled CTD casts, and the standard deviations of the averages within the profile was decreased by as much as 4.4 fold using this approach. Finally, the drift-corrected ISUS output voltage profiles were correlated with bottle-collected nitrate concentrations at each station to yield the ISUS-estimated nitrate profiles. Comparison of these ISUS-estimated concentrations with the bottle-collected nitrate concentrations showed that the ISUS results matched the bottle results within $+/-0.28 \mu \mathrm{M}$. The degree of precision of the final ISUS nitrate profiles as well as the high data density allowed a much better evaluation of the distribution of nutrients in this region of the Arctic Ocean.

Because of the need for nutrient data suites with high data density, we believe that the optical method of measuring nitrate is of considerable value. The brand of instrument used in this study (the ISUS by Satlantic, Inc) gave us high quality results, but only after considerable effort. We recommend that the engineering of the ISUS be reexamined for greater ease of use. First, the initial surge in electrical current demand when the ultraviolet lamp is activated can be corrected electronically, as we have done with our units and apparently has been done to the latest models of the Satlantic ISUS. Secondly, the large current demand of the instrument is also an impediment, since many CTD power supplies lack capacity for auxiliary current demands required by the ISUS. Finally, the drift of the output signal of our instrument during its first hour of operation was a difficulty which we were able to counter because of the manner in which we did station casts (by repeatedly lowering and raising the sensor package for the collection of the water samples). This procedure is not commonly done because of the demands on shiptime. Again, an engineering examination should determine the source of this warm-up drift and develop the electronics or algorithms to minimize it. Nevertheless, we emphasize that with care, this instrument was able to supply nitrate data of sufficient quality and greatly enhanced density which allowed us to better understand the ocean we studied.

\section{ACKNOWLEDGMENTS}

This research was supported by NSF grants \# 0125306, 0125313 , and 0352641 to the authors.

\section{ABBREVIATIONS}

$\begin{array}{lll}\mathrm{CTD} & = & \text { Conductivity, Temperature, and Depth } \\ \text { ISUS } & = & \text { In Situ Ultraviolet Spectrophotometer }\end{array}$

\section{REFERENCES}

[1] Buck RP, Singhadeja S, Rogers LB. Ultraviolet absorption spectra of some inorganic ions in aqueous solutions. Anal Chem 1954; 26: 1240-2.

[2] Armstrong FAJ, Boalch GT. The ultra-violet absorption of seawater. J Mar Biol Assoc U K 1961; 41: 591-7.

[3] Ogura N, Hanya T. Nature of ultra-violet absorption in sea water. Nature (London) 1966; 212: 758.

[4] Thomas O, Gallot S, Mazas N. Ultraviolet multiwavelength absorptiometry (UVMA) for the examination of natural waters and waste waters: Part II: determination of nitrate. Fresenius J Anal Chem 1990; 338: 238-40.

[5] Holm TR, Kelley WH, Sievers LR, Webb DL. A comparison of ultraviolet spectroscopy with other methods for the determination of nitrate in water. Spectroscopy 1997; 12: 38-45.

[6] Finch MS, Hydes DJ, Clayson CH, Weigl B, Dakin J, Gwillam P. A low power ultra violet spectrophotometer for measurement of nitrate in seawater: Introduction, calibration and initial sea trials. Anal Chim Acta 1998; 377: 167-77.

[7] Clayson CH. Sensing of nitrate concentration by UV absorption spectrophotometry. In: Varney M, Ed. Chemical sensors in oceanography. Gordon and London: Breach 2000; pp. 107-21.

[8] Sandford RC, Exenberger A, Worsfold PJ. Nitrogen cycling in natural waters using in situ, reagentless UV spectrophotometry with simultaneous determination of nitrate and nitrite. Environ Sci Technol 2007; 41: 8420-5.

[9] Rieger L, Vanrolleghem PA, Langergraber G, Kaelin D, Siegrist H. Long-term evaluation of a spectral sensor for nitrite and nitrate. Water Sci Technol 2008; 57(10): 1563-9.

[10] Karlsson M, Karlberg B, Olsson RJO. Determination of nitrate in municipal waste water by UV spectroscopy. Anal Chim Acta 1995; 312: 107-13.

[11] Johnson KS, Colettii LJ. In situ ultraviolet spectrophotometry for high resolution and long-term monitoring of nitrate, bromide and bisulfide in the ocean. Deep-Sea Res I 2002; 49: 1291-305.

[12] Sakamoto CM, Johnson KS, Coletti LJ. Improved algorithm for the computation of nitrate concentrations in seawater using an in situ ultraviolet spectrophotometer. Limnol Ocean Methods 2009; 7: $132-43$.

[13] Thompson TG, Korpi E. The bromine-chlorinity ratio of sea water. J Mar Res 1942; 5: 28-36.

[14] Morris AW, Riley JP. The bromide/chlorinity and sulfate/chlorinity ratio in sea water. Deep-Sea Res I 1966; 13: 699-705.

[15] Christensen J, Melling H. Helo Survey CTD Data. Data report in the Arctic System Science data repository at the Earth Observing Laboratory of University Consortium for Atmospheric Research 2003. Available from: http://data.eol.ucar.edu/codiac.

[16] Christensen J, Melling H. Helo Survey ISUS Nitrate Concentrations, Temperature, Salinity, and Density. Data report in the Arctic System Science data repository at the Earth Observing Laboratory of University Consortium for Atmospheric Research 2003. Available from: http://data.eol.ucar.edu/codiac

[17] Christensen J, Melling H. Helo Survey Nutrients and Oxygen Isotope Samples. Data report in the Arctic System Science data repository at the Earth Observing Laboratory of University Consortium for Atmospheric Research 2003. Available from: http://data.eol.ucar.edu/codiac

[18] Hufford GL. On apparent upwelling in the Southern Beaufort Sea. J Geophys Res 1974; 79: 1305-6.

[19] Johnson WR. Current response to wind in the Chukchi Sea: a regional coastal upwelling event. J Geophys Res 1989; 94: 205764.

[20] Christensen JP, Shimada K, Semiletov I, Wheeler PA. Chlorophyll response to shelf-break upwelling and winds in the Chukchi Sea, Alaska, in autumn. Open Oceanogr J 2008; 2: 34-53. 